FULL LENGTH RESEARCH ARTICLE

\title{
THE BIRD SPECIES OF PANDAM WILDLIFE PARK AND THE SURROUNDING FARMLANDS
}

\author{
DAMI, F. D. ${ }^{1} \&$ MANU, S.A. ${ }^{2}$ \\ ${ }^{1}$ Department of Zoology, University of Jos, P.M.B.2084, Jos, Nigeria \\ ${ }^{2}$ A.P. Leventis Ornithological Research Institut, Department of Zoology, University of Jos, Nigeria \\ damidanjuma@yahoo.com
}

\begin{abstract}
This study investigated the bird species abundance and diversity of the Pandam wildlife park and the surrounding farmlands. The effect of time of day as well as vegetation variables on bird species diversity in the park and surrounding farmlands was also conducted. 10 transects in each study site were surveyed twice between during the dry season and vegetation variables (trees, fingers, finger-rings two- hand, grazing, farming, canopy cover, ground cover, litter cover, diameter breast height) measured. Results showed that there was a significant difference in bird species diversity between the park and the surrounding farmlands (Wicoxon test, $z=-1.961, p=0.050$ ). That time of day had a significant effect on the number of birds seen with the number of birds seen reducing as time approaches midday (Kruskal-Wallis 1 -way ANOVA, $\chi^{2}=59.651, d f=7, p<0.001$ ). Trees, canopy, ground cover and litter cover were positively correlated to, and had a significant effect on bird species diversity in the park (trees: $F_{1,10}=9.942$, $P=0.014$; litter cover: $F_{1,10}=15.521, P=0.004$; ground cover: $F_{1,10}=16.868, P=0.003$ and canopy: $F_{1,10}=15.487, P=0.004$ ), while in the farmland there was no positive correlation of bird species diversity with any of the vegetation variable, trees $(r=0.210, N=10$, $p=0.560)$; finger ( $r=0.038, N=10, p=0.917)$; ring $(r=0.48, N=10 p=0.229)$; two hand $(r=0.058, N=10, p=0.874)$; grazing $(r=-0.141$, $\mathrm{N}=10, p=0.697)$; farming $(r=-0.243, N=10, p=0.500) ; \log (r=-0.183, N=10, p=0.614)$; shrubs $(r=-0.352, N=10, p=0.319)$; stumps $(r=0.195, N=10, p=0.590)$. Bird diversity index of 3.11 (park) and 3.05 (farmland) is not good enough for an IBA, because the park has been greatly degraded and there was no significant difference in bird diversity index between the park and the surrounding farmlands.
\end{abstract}

Keywords: Birds, farm species, wildlifepark, species abundance, vegetation variables, species diversity

\section{INTRODUCTION}

Pandam Wildlife Park is as an Important Bird Area (IBA), with the lake and surrounding environments supporting about 217 bird species and several species of mammals and plant (Ezealor 2002). However, the growing need to support a rapidly expanding human population has led to a potential conflict in priorities between agricultural development, firewood collection, grazing, hunting and the nurturing of wildlife as a source of foreign revenue and the protection of biodiversity. Thus the demand for firewood, grazing and agricultural land has encouraged encroachment into the area. The result of these activities is loss of biological diversity (Dranzoa 1998).

Despite the fact that energy is a limiting commodity for many communities in the developing world, with the rural communities in Africa highly depending upon wood as their primary energy source (Du Plessis 1995), only few studies have been carried out in Africa on the effects of logging on bird species diversity (Dranzoa 1998; Du Plessis 1995). Deforestation, introduced species, direct exploitation of forest resources such as animals for bush meat and wood for fuel have been shown to have a negative effect on the bird species diversity (Brooks et al. 2002, Du Plessis 1995, Dranzoa 1998, Eeley et al. 2001).

Presently, there are few African studies that assessed the effect of forest fragmentation (e.g. Nenmark 1990), while no study has been carried out on the bird species diversity of the forests or reserves in Nigeria except the work of Manu (2001) on fragmentation.

The aim of the study is to determine if there is any significant difference in bird species diversity between the Pandam Wildlife park and the surrounding farmlands, as well as to ascertain if vegetation variables have any significant effect on the bird species diversity in the different sites.

\section{MATERIALS AND METHODS:}

Study area: Pandam Wildlife Park $\left(08^{\circ} 40\right.$ and $09^{\circ} 03^{\prime} \mathrm{E}$ and altitude $175-315 \mathrm{~m}$ ) is owned by the Plateau State government of Nigeria and located in Quan-Pan Local Government Area (LGA), covering a total area of 2240 ha (Ezealor 2002). Two rivers, the Dep and the Li, drain the park, and join before emptying into the Benue. The land slopes gradually southwards and forms a basin (Pandam Lake) which is a wetland complex of approximately $2 \mathrm{~km}^{2}$. The vegetation of the park is typical Sudan-Guinea savanna with gallery forests in riparian areas. The surrounding farmlands have scattered trees and some bush. Crops cultivated include maize, yam, guinea corn, beans and cassava. Grazing also occurs in the farmlands.

Sampling technique: Line transect method was used as the bird census technique. Twenty transects were systematically selected, 10 transects in the wildlife park and 10 transects in the surrounding farmlands. A total length of $21,000 \mathrm{~m}$ in the park and $20,400 \mathrm{~m}$ in the farmland was surveyed including repeat visits. Before beginning censuring, a preliminary survey was conducted for two weeks to become familiar with the birds, their songs and calls in the areas. Surveys were carried out in the dry season (February-April) during the early morning, starting soon after dawn. The start and end time for each transect as well as the start and end time for each $100 \mathrm{~m}$ section was recorded.

On each transect during each visit, records of birds seen or heard were recorded. A pair of binoculars was used to confirm identification 
of birds located by eye. The numbers of bird species seen or heard from the transect line was recorded. Birds flying over transect were recorded as seen, as well as singing and mixed species parties. Count information was recorded separately for each $100 \mathrm{~m}$ section of each transects.

As bird survey was going on, $100 \mathrm{~m}$ sections in each transects were also marked using colour ribbons that was later used for vegetation measurements.

\section{Vegetation measurement}

Wildlife park: At the start of each 100 m section, the number of trees in a $10 \mathrm{~m}$ square plot at the beginning of the section was recorded. A total of 5 quadrats $(2 \times 2 \mathrm{~m})$ were randomly selected within the $10 \mathrm{~m}$ square plot by throwing a stick over the shoulder of the observer and the following measurements made from each quadrat:

(i) The percentage ground cover (to the nearest 5\%) estimated by eye (ii) the percentage visible sky (by viewing the sky through the canopy from the wrong side of a pair of binoculars (see Jones et al. 1996) (iii) the number of trees with less than $1 \mathrm{~cm}$ (finger), $1-10 \mathrm{~cm}$ (ring), and greater than $10 \mathrm{~cm}$ (2 hand) diameter trunks above $1 \mathrm{~m}$ in height (iv) the Diameter Breast Height (DBH) using the carpenter's tape $(v)$ the percentage litter (to the nearest $5 \%$ ) estimated by eye. The vegetation measurements for each $100 \mathrm{~m}$ section was taken alternately along transect lines.

Farmland: at the start of each $100 \mathrm{~m}$ section of each transect, the number of trees, finger, ring, 2 hand, presence or absence of grazing and farming, crop type cultivated, number of logs, shrubs and stumps were recorded.

\section{RESULTS}

A total of 7,403 birds were observed comprising 134 species.

Effect of time of day on bird species: Fig. 1 showed the effect of time of day on the mean number of bird species encountered. It showed that more birds were encountered in the early hours of the day. There was a significant effect of time of day on the number of bird species recorded between $06.00 \mathrm{hr}$ and $10.00 \mathrm{hr}$ (Kruskal-Wallis 1-way ANOVA, $\chi^{2}=59.651, d f=7, p<0.001$ ).

Distribution of bird species and their relative abundance in within the park and surrounding Farmlands: The distribution of species and relative abundance in the park and surrounding farmlands is shown in Fig. 2. There was a significant difference in the relative abundance between park and surrounding farmlands (Kruskal-Wallis 1 -way ANOVA, $\left.\chi^{2}=144.110, \mathrm{df}=1, p<0.001\right)$.

Bird species diversity: Table 1 showed diversities in farmlands and the park in the 10 transects taken in each study site. There was significant difference in bird species diversity between the Wildlife Park and the surrounding farmlands (Wicoxon test, $z=-1.961, p=0.050$ ). The mean diversity showed the park to have a higher diversity (3.11) than farmland (3.054).

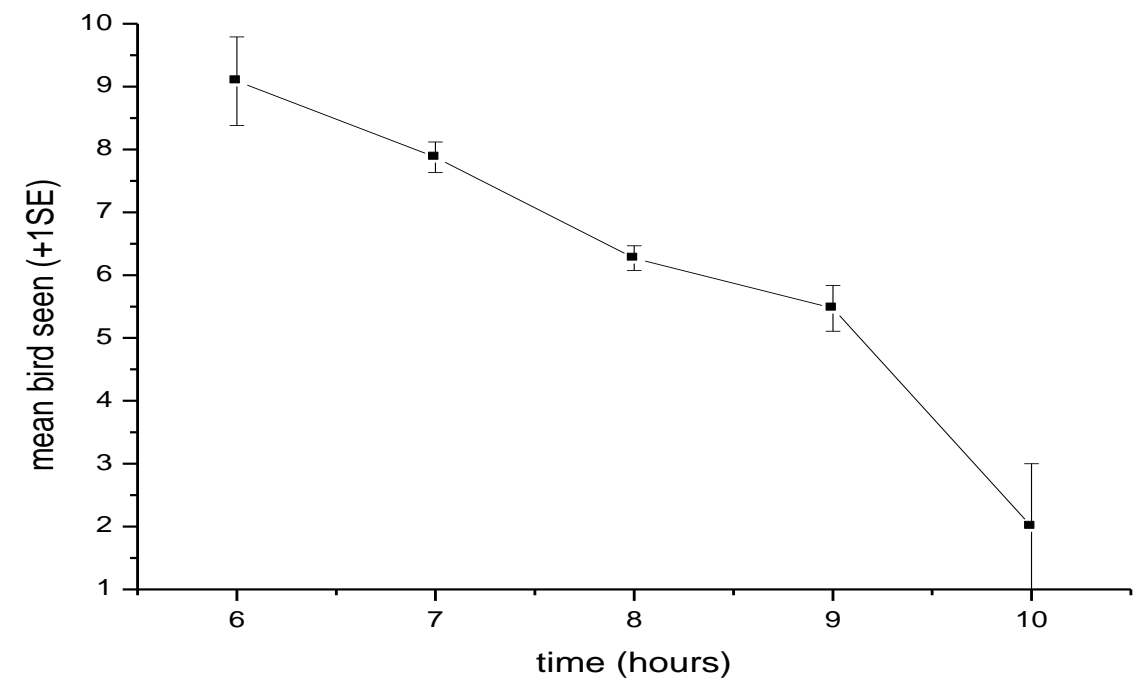

FIG. 1. THE EFFECT OF TIME OF DAY ON MEAN NUMBER OF BIRD SPECIES RECORDED ON TRANSECTS.

\section{TABLE 1: MEAN NUMBER OF BIRD SPECIES AND TOTAL NUMBER} OF BIRDS OBSERVED ( \pm 1 SE)

\begin{tabular}{lcc}
\hline Site & Mean number of bird species & $\begin{array}{c}\text { Total number of bird } \\
\text { species }\end{array}$ \\
\hline Park & $39.90( \pm 0.108)$ & 3261 \\
Farmland & $42.50( \pm 0.114)$ & 4142
\end{tabular}




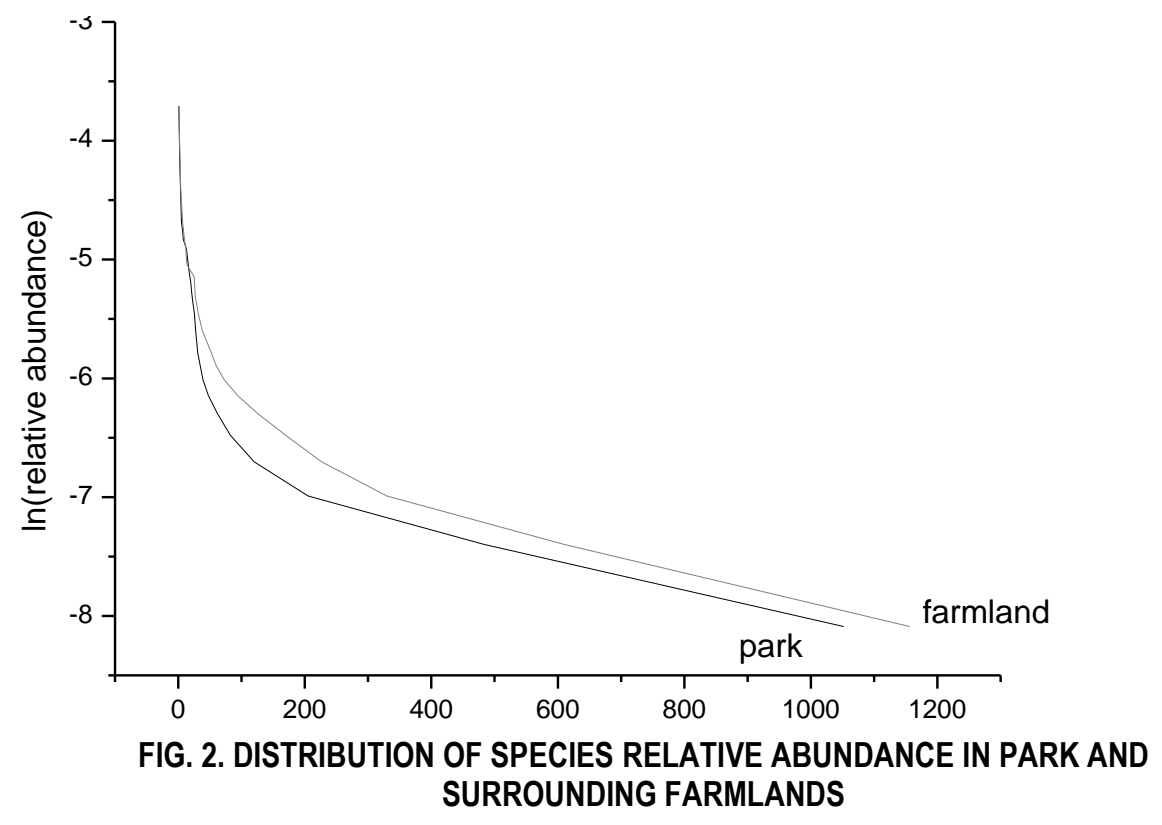

TABLE 2: DIVERSITY IN FARMLAND AND PARK

\begin{tabular}{lll}
\hline $\begin{array}{l}\text { Transect } \\
\text { sections }\end{array}$ & Park & Farmland \\
\hline 100 & 3.42 & 2.04 \\
200 & 2.92 & 3.22 \\
300 & 3.07 & 3.23 \\
400 & 3.32 & 3.18 \\
500 & 3.34 & 3.15 \\
600 & 3.31 & 3.20 \\
700 & 3.39 & 3.07 \\
800 & 3.67 & 3.16 \\
900 & 3.34 & 3.27 \\
1000 & 3.26 & 3.31 \\
1100 & 2.53 & 1.91 \\
1200 & 2.03 & 1.31 \\
1300 & 1.64 & - \\
\hline
\end{tabular}

Effects of vegetation variables on diversity: Tables 3 and 4 present means of vegetation variables and diversity in park and farmland respectively. Vegetation variables and the diversity in both study sites were found to have a normal distribution. Pearson rank correlation for vegetation variables in the park showed that trees, litter cover, ground cover and canopy had a positive correlation with diversity. A GLM analysis of variance showed that they all have a significant effect on bird species diversity (trees: $F_{1,10}=9.942, P=0.014$; litter cover: $F_{1,10}=15.521$, $P=0.004$; ground cover: $F_{1},{ }_{10}=16.868, P=0.003$ and canopy: $F_{1}$, $\left.{ }_{10}=15.487, P=0.004\right)$.

No vegetation variable in the farmland showed positive correlation with bird species diversity, trees $(r=0.210, N=10, p=0.560)$; finger $(r=0.038$, $\mathrm{N}=10, p=0.917)$; ring $(\mathrm{r}=0.48, \mathrm{~N}=10 \mathrm{p}=0.229)$; two hand $(\mathrm{r}=0.058, \mathrm{~N}=10$, $p=0.874)$; grazing ( $r=-0.141, N=10, p=0.697)$; farming $(r=-0.243, N=10$, $\mathrm{p}=0.500) ; \log (\mathrm{r}=-0.183, \mathrm{~N}=10, \mathrm{p}=0.614) ;$ shrubs $(\mathrm{r}=-0.352, \mathrm{~N}=10$, $\mathrm{p}=0.319)$; stumps $(\mathrm{r}=0.195, \mathrm{~N}=10, \mathrm{p}=0.590)$ but interactions amongst them showed some positive relationships.
Finger, ring, two-hand, grazing, shrubs and stumps that showed positive relationships were modelled into the GLM analysis of variance. Stumps and shrubs were found to have significant effect on bird species diversity in the farmlands (Table 5)

\section{DISCUSSION}

A large number of bird species can be accommodated in an environment at two extremes: Each species may have different habitat preference and feed throughout this habitat on all kinds of food, or, all the species may share the entire habitat, with each species feeding on a variety of food or in a different situation within the habitat. It is hard to say just where the balance of these opposing requirements would be reached, but it is clear that greater specialization resulting in increased efficiency would always be favoured as long as no time or energy is wasted. And no time or energy will be wasted if a natural route consisting of feeding places distinctly separates niches. 
TABLE 3: MEAN VALUES OF VEGETATION VARIABLES AND DIVERSITY (H) IN PARK.

\begin{tabular}{|c|c|c|c|c|c|c|c|c|c|c|}
\hline Trans. No & $\mathrm{H}$. & $\begin{array}{c}\text { Tree } \\
\text { Quadr. }\end{array}$ & Finger. & Ring. & 2hand. & Litcov. & Grdco. & Canop. & Dbh. & Clim. \\
\hline 1 & 3.18 & 3.00 & 1.30 & .48 & .50 & 56.12 & 1.94 & 50.70 & 22.04 & 2.14 \\
\hline 2 & 3.16 & 3.00 & 2.12 & 1.08 & .56 & 45.40 & 1.14 & 40.70 & 20.50 & 4.28 \\
\hline 3 & 3.29 & 3.00 & 1.30 & .34 & .36 & 42.20 & .96 & 47.80 & 15.48 & .62 \\
\hline 4 & 3.07 & 3.00 & .44 & .56 & .60 & 44.00 & 1.34 & 51.40 & 12.78 & .20 \\
\hline 5 & 3.35 & 3.00 & 6.18 & 1.71 & .65 & 52.54 & 2.37 & 47.32 & 11.25 & .82 \\
\hline 6 & 2.46 & 3.00 & .57 & .37 & .14 & 8.29 & 7.20 & 9.71 & 4.46 & .00 \\
\hline 7 & 3.22 & 3.00 & 1.00 & .44 & 1.24 & 42.22 & .93 & 70.44 & 23.98 & .96 \\
\hline 8 & 3.15 & 3.00 & .93 & .55 & .58 & 35.82 & 3.68 & 42.08 & 24.00 & 1.20 \\
\hline 9 & 3.18 & 3.00 & .44 & .38 & .42 & 37.54 & 2.84 & 47.50 & 15.06 & .08 \\
\hline 10 & 3.04 & 3.00 & .15 & .51 & .55 & 53.27 & 1.69 & 39.09 & 8.71 & .40 \\
\hline
\end{tabular}

Trans. No.=Transect number. Quadr. =Quadrat, 2hand=Two-hand, Litcov=Litter cover, Grd.co=Ground cover, Dbh=Diameter Breast Height, Clim=Climbers

TABLE 4: MEAN VALUES OF VEGETATION VARIABLES AND DIVERSITY IN FARMLANDS.

\begin{tabular}{|c|c|c|c|c|c|c|c|c|c|c|}
\hline rans. No & $\mathrm{H}$. & Trees. & Finger. & Ring. & 2hand. & Graz. & Farm. & Log. & Shrub. & Stumps \\
\hline 11 & 3.03 & 1.20 & .30 & .50 & .10 & 1.00 & 1.00 & .10 & 6.30 & 1.10 \\
\hline 12 & 3.09 & .60 & 1.30 & 2.90 & 1.80 & .90 & .90 & .00 & 9.80 & 1.70 \\
\hline 13 & 3.01 & 1.20 & 1.80 & 2.50 & .80 & .90 & .80 & .10 & 10.10 & 1.30 \\
\hline 14 & 3.02 & .80 & 2.80 & 2.10 & 1.80 & 1.00 & .90 & .40 & 9.90 & 1.60 \\
\hline 15 & 3.04 & .70 & .20 & .90 & .20 & .70 & 1.00 & .20 & 1.10 & .70 \\
\hline 16 & 3.31 & 1.50 & 4.83 & 6.75 & 1.17 & .83 & .92 & .25 & 2.33 & .92 \\
\hline 17 & 3.10 & 1.90 & .00 & .70 & .80 & .30 & 1.00 & .00 & 1.30 & .70 \\
\hline 18 & 2.85 & 1.40 & 1.20 & 1.20 & .50 & .80 & 1.00 & .30 & 5.90 & .30 \\
\hline 19 & 3.09 & 1.60 & 17.00 & 4.30 & 2.70 & 1.00 & .80 & .20 & 8.50 & 1.30 \\
\hline 20 & 3.00 & 1.10 & 20.10 & 7.90 & 3.90 & 1.00 & 1.00 & .20 & 9.00 & 1.40 \\
\hline
\end{tabular}

Graz=Grazing, Canop=Canopy and H=Diversity.

TABLE 5: RESULTS OF GLM SHOWING EFFECTS OF STUMPS AND SHRUBS ON BIRD SPECIES DIVERSITY IN FARMLANDS.

\begin{tabular}{llll}
\hline $\begin{array}{l}\text { Significance at } \\
\text { O.05 level }\end{array}$ & $\begin{array}{l}\text { Type III sum of } \\
\text { squares }\end{array}$ & Df. & F. \\
\hline $\begin{array}{l}\text { Correction } \\
\text { model } \\
0.033\end{array}$ & $7.518 \mathrm{E}-02$ & 2 & 5.809 \\
$\begin{array}{l}\text { Intercept } \\
0.000\end{array}$ & 11.283 & 1 & 1743.405 \\
$\begin{array}{l}\text { Shrubs } \\
0.013\end{array}$ & $7.061 \mathrm{E}-02$ & 1 & 10.911 \\
Stumps & & & \\
0.019 & $6.026 \mathrm{E}-02$ & 1 & 9.312 \\
Error & $4.530 \mathrm{E}-02$ & 7 & \\
Total & 93.370 & 10 & \\
Corrected Total & 0.120 & 9 & \\
\hline
\end{tabular}


Thus, natural selection would tend to eliminate a situation in which bird species diversity is dependent on tree species diversity, unless, in some fruit eating species (MacArthur \& MacArthur1961). Results from this study clearly accept this position. In the farmlands, trees were not positively correlated to bird species diversity but were positively correlated with bird species diversity in park.

The farmland had higher abundance of bird species compared to the park probably because of temporal food abundance. However, a study in different seasons over a longer period of time will show the effects better. There was a significant difference between the bird species diversity in the park and the surrounding farmlands. In the park various trees of different heights, herbs and bushes provide different heights above the ground hence have bird diversity predictable from the height profile for which species are specialized. But this difference is not marked for an important bird area as the Pandam Wildlife Park even though we expect to have species that are peculiar with the farmlands. This is because the Park is undergoing modification from human activities in form of tree felling for firewood, poaching and grazing. Up to the time of this survey these activities are still taking place with management of the park battling to control. These activities have so much degraded the park such that at certain points there is no much difference between the park and the surrounding farmlands. Sites with high bird species diversity have their resources divided among more species and the share of each species is small while at sites with lower consumer diversity, the species present can avail themselves of resources that would otherwise have gone to absent competitors, and they are thereby able to maintain higher densities (Cody 1983)

Berg (1997) found that species-richness was positively correlated with both area and habitat heterogeneity but not with measures of habitat diversity. He also found that total density of birds was higher in fragments than in forest sites where several species with high densities in fragments than in forest sites forage in farmland areas surrounding the sites, so the areas actually used by these birds are larger than those of the forest fragments.

Many studies have confirmed that for terrestrial communities the numbers of bird species, as well as their diversity are strongly positively correlated with aspects of the structural complexity of vegetation (vegetation variables) (MacArthur 1964; Recher 1969; Karr \& Roth 1971). That is, the more complex the structure of composition of the vegetation, the more likely it is that the habitat will contain more bird species.

Vegetation cover was more complex in the Park where vegetation variables where trees, litter cover, ground cover and canopy cover had a strong positive correlation with bird species diversity. The vegetation variables also had a significant effect on bird species diversity. On the other hand the surrounding farmlands that have a lower vegetation structure complexity did not show any positive correlation between vegetation variables and bird species diversity. Good vegetation can provide good protection from predators and a high diversity of insects at different stages of their life cycles, which means, a continuous supply of food for insectivorous birds. Trees in these habitats also flower at different times of the year and this means fruiting trees are always available for frugivorous birds like African Green Pigeon, Green Turaco and African Grey Hornbill. Flowering trees also ensure nectar diet for nectarivores such scarlet chested sunbird. Seasonal fluctuation in the flowering and fruiting of plant species is also known to influence the distribution and abundance of many bird species, especially the highly mobile nectarivous species (Woinarski et al. 1988).

Tree canopy and cover were shown to have a positive correlation and significant effect on bird species diversity in the park but not the farmlands. This might be because of clearing activity associated with farming practices, which reduces canopy. It could also be due to the effect of the dry season during which this survey was conducted when vegetation cover was poor. A similar study in the rainy season and in between seasons might be interesting.

\section{REFERENCES}

Berg, A. 1997. Diversity and abundance in relation to forest fragmentation, habitat quality and heterogeneity. Bird Study, 44:355366.

Brooks, T., Balmford, A., Burgess, N., Fjeldsa, J., Hansen, L. A., Moore, J., Rahbek, C. \& Williams, P. 2001. Towards a blueprint for conservation in Africa. Bioscience, 51:613-624.

Cody, L. M. 1983. Bird diversity and density in South African forests, Oecologia, 59:201-215.

Dranzoa, C. 1998. The avifauna 23 years after logging in Kibale National Park, Uganda. Biodiversity and conservation 7:777-797.

Du Plessis, A. 1995. The effect of fuelwood removal on the diversity of some cavity-using birds and mammals in South Africa. Biological Conservation 74:77-82.

Eeley, A. C. H., Lawes, J. M. \& Reyes, B. 2001. Priority areas for conservation of subtropical forests in South Africa: A case study from Kwazulu-Natal. Biodiversity and Conservation 10:1221-1246.

Ezealor, A. U. (2002) Critical sites for conservation in Nigeria. Nigerian Conservation Foundation, Lagos, Nigeria. Pp.46-47.

Jones, P., Vickery, J., Holt, S. \& Cresswell, W. 1996. A preliminary assessment of some factors influencing the density and distribution of palaectic migrants wintering in the sahel zone of West Africa. Bird Study, 43:73-84.

Karr, J. R. \& Roth, R. R. 1971. Vegetation structure and avian diversity in several New World areas. American Naturalist, 105:423-435.

MacArthur, J. W. 1964. Environmental factors affecting species diversity. American Naturalist, 98:387-397.

MacArthur, R. H. \& MacArthur, J. W. 1961. On bird species diversity. Ecology, 42:594-598.

Manu, S. 2001. Possible factors influencing the decline of Nigeria's rarest endemic, the Ibadan Malimbe Malimbus ibadanensis. Ostrich, $15: 119-121$

Newmark, W. D. 1990. Tropical forest fragmentation and the local extinction of understory birds in eastern Usambara Mountains, Tanzaura. Conservation Biology 5: 67-77.

Recher, H. F. 1969. Bird species diversity and habitat diversity in Australia and North America. American Naturalist 103: 75-80. 